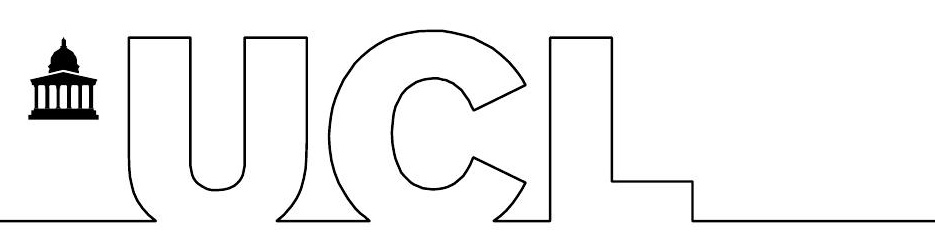

Poon, DS; Reich, E; Smith, VM; Kingston, J; Reddy, MA; Hungerford, JL; Sagoo, MS; (2015) Ruthenium-106 Plaque Brachytherapy in the Primary Management of Ocular Medulloepithelioma. Ophthalmology, 122 (9) pp. 1949-1951. 10.1016/j.ophtha.2015.03.002. Downloaded from UCL Discovery: http://discovery.ucl.ac.uk/1467161

\title{
ARTICLE
}

\section{Ruthenium-106 plaque brachytherapy in the primary management of ocular medulloepithelioma}

Daniel S. Poon ${ }^{1}$, Ehud Reich ${ }^{1,2,3}$, Victoria M. Smith ${ }^{1}$, Judith Kingston ${ }^{4}$, M. Ashwin Reddy ${ }^{1,2}$, John L. Hungerford", Mandeep S. Sagoo ${ }^{1,2,3,5,{ }^{*}}$

${ }^{1}$ Royal London Hospital, London, UK

${ }^{2}$ Moorfields Eye Hospital, London, UK

${ }^{3}$ St. Bartholomew's Hospital, London, UK

${ }^{4}$ Great Ormond Street Hospital, London, UK

${ }^{5}$ UCL Institute of Ophthalmology, London, UK

"Address for reprints: Mr Mandeep S. Sagoo, MB, PhD, FRCS (Ed), FRCOphth, Moorfields Eye Hospital, City Road, London, EC1V 2PD, UK; Telephone: 0207253 3411; Fax: 020

7900 2927; E-mail: mandeep.sagoo@moorfields.nhs.uk

Revision as Manuscript to Report (Invited) of MS 2014-1997

Meeting presentations:

International Society of Ocular Oncology, Cleveland, OH, USA 2013

British and Irish Paediatrics Ocular Association, annual meeting, Leeds, UK, 2013

World Ophthalmology Congress, Tokyo, Japan, 2014

\section{Financial support:}

None

\section{Conflict of interest:}

No conflicting relationship exists for any author

\section{Running heading:}

Plaque brachytherapy for medulloepithelioma

Ocular medulloepithelioma (or diktyoma) is a rare intraocular tumour of the non-pigmented ciliary epithelium, typically unilateral and usually in childhood. This benign or malignant tumour, derived from the medullary neuroepithelium of the embryonic optic cup, is nonteratoid (containing only epithelium) or teratoid (containing neural, cartilaginous and bone material). Anterior chamber or orbital invasion is possible.

In 1988, our group reported our experience with iridocyclectomy or enucleation as the primary treatment. In 16 cases, 4 underwent iridocyclectomy, but eventually all required enucleation. ${ }^{1}$ Other reports had similar findings. ${ }^{2}$ Recently, reports have claimed successful treatment with resection and adjuvant brachytherapy ${ }^{3}$ or brachytherapy alone ${ }^{4}$ using the radioisotope lodine-125. We evaluated our recent series of cases treated with Ruthenium106 plaque brachytherapy in the primary management of medulloepithelioma. 
A retrospective medical record review was performed of consecutive patients with medulloepithelioma at the paediatric ocular oncology service at Moorfields Eye Hospital and the Royal London Hospital (Clinical Effectiveness Unit of Barts Health NHS Trust number 5398). There were 6 patients (4 male) diagnosed with medulloepithelioma between January 2005 and December 2012. The mean (median, range) age of presentation was 58 (55, $9-$ 141) months. The referring diagnosis, medical history and clinical features (Figure 1) are detailed in Table 1 (available at http://aaojournal.org). All patients presented with a mass or cystic lesion, with involvement of $4(4,2-9)$ clock hours. The B scan height was 4.0 (3.6, 3 - 5.9) $\mathrm{mm}$. Lens notch was present $50 \%$, sectoral cataract in $33 \%$, and anterior synechiae in $17 \%$. Intraocular pressures were normal. Retrolental thickened cyclictic membrane was absent. $^{5}$

The diagnosis was known in only Patient 6, after vitreolensectomy and fine needle aspiration biopsy elsewhere. Due to a rapidly enlarging mass, scleral thinning, iris neovascularisation, ectropion uveae and vitreous seeds this eye was enucleated. The histopathology findings were of a tumour composed of ribbons of pseudostratified cells, with numerous mitoses. There were areas of necrosis with undifferentiated sheets of cells, with occasional rosette formation. There was a focus of choroidal and early scleral invasion, so adjuvant systemic chemotherapy was given and the child remains metastasis free.

Plaque brachytherapy was performed in the remaining 5 eyes (by JLH or MSS) with $12 \mathrm{~mm}$ circular ruthenium-106 applicators (Bebig, Germany), delivering a tumour apex radiation dose of $40-50$ Gy. All tumours reduced in height, and change in B scan tumour height was $-1.0(-1.0,-0.2--1.4) \mathrm{mm}$. Regression $(>0.5 \mathrm{~mm}$ in reduction in $\mathrm{B}$ scan height) occurred in 4 out of 5 eyes $(80 \%)$. In 1 tumour the reduction in height was $0.2 \mathrm{~mm}$, deemed stable. During follow-up of $26(14,9-57)$ months, there were no cases of tumour relapse, corneal oedema, raised intraocular pressure, progression of cataract, secondary enucleation or regional or distant metastasis. Iris neovascularisation was seen in 1 eye at 11 months after plaque brachytherapy, while non-proliferative retinopathy was diagnosed in another eye at 12 months. Visual acuity (Table 2 available at http://aaojournal.org) remained stable or improved in 4 out of 5 eyes (80\%) and in 1 case amblyopia had developed before diagnosis, with no response to patching the better eye.

Our series of 6 cases managed over 7 years, concurs with two other international centres that treated 31 cases over 42 years and 10 cases in 12 years respectively. ${ }^{5}$ Initial misdiagnosis, unnecessary surgical procedures and delayed referral occur frequently. ${ }^{2,5}$ Similarly, in the current series only one patient was referred with the correct diagnosis. The majority of cases in the literature have been treated with enucleation. ${ }^{1,5}$ Partial lamellar sclerouvectomy (PLSU) or iridocyclectomy is a treatment option for circumscribed lesions, but it carries a high rate of recurrence. ${ }^{1,2}$ Cryotherapy has been reserved in some cases for small lesions or minor local recurrences. ${ }^{2}$

The use of radiotherapy in medulloepithelioma has been evaluated before. External beam radiotherapy was to salvage eyes after surgical resection or as adjuvant therapy in eyes with extrascleral or orbital extension. ${ }^{1}$ The use of plaque brachytherapy has received sparse attention in the literature. Two reports described its use as an adjuvant therapy after PLSU in three patients. ${ }^{2,3}$ Only in one such instance was it possible to avoid subsequent enucleation. ${ }^{3}$ Another case report described the situation where the medulloepithelioma responded to iodine-125 brachytherapy, avoiding planned PLSU. ${ }^{4}$ The role and safety of ruthenium-106 plaque brachytherapy alone has not yet been reported. The idea of using this $\beta$-radiation emitting isotope is an attractive one, since its complication profile is less than that of the $x$ ray and $y$-emitting iodine-125 or of charged particles. In a recent report of 41 cases, plaque brachytherapy was used as a primary treatment in 3 eyes with medulloepithelioma 
with good tumour control. ${ }^{5}$ However, the radioisotope used was not stated. As in other reports, we chose a radiation dose of 40-50Gy. ${ }^{4,5}$ Previously Cassoux and colleagues gave a dose of 25Gy to the tumour apex but applied this dose twice. ${ }^{3}$ Our larger height tumours were given 50Gy to the apex, to ensure sufficient coverage of the tumour.

In the current series all brachytherapy treated tumours had a height under $5 \mathrm{~mm}$, and $80 \%$ regressed. During 26 months follow-up, none of the eyes required enucleation or relapsed. These cases were less advanced without diffuse retrolental cyclitic membranes, which may explain our rate of tumour control. As the tumours were small, the change in height is also small. A biopsy was not performed, so it is impossible to comment on the presence of malignant cells. However, the rationale for brachytherapy is to neutralise any malignant components. It is likely that this has been achieved, as there were no cases of local or systemic relapse. With longer follow-up there is a possibility of recurrence or complications, such as cataract progression or neovascularisation that require further intervention.

Our results suggest that Ruthenium-106 plaque brachytherapy achieved excellent tumour control, avoiding enucleation and sparing vision. The long-term implications of plaque brachytherapy are currently unknown, but as metastasis is relatively uncommon, we believe that plaque brachytherapy coupled with careful surveillance is appropriate in the initial management of a small-localised medulloepithelioma.

\section{References}

1. Canning CR, McCartney AC, Hungerford J. Medulloepithelioma (diktyoma). $\mathrm{Br} \mathrm{J}$ Ophthalmol 1988;72(10):764-7.

2. Shields JA, Eagle RC, Jr., Shields CL, Potter PD. Congenital neoplasms of the nonpigmented ciliary epithelium (medulloepithelioma). Ophthalmology 1996;103(12):19982006.

3. Cassoux N, Charlotte $F$, Sastre $X$, et al. Conservative surgical treatment of medulloepithelioma of the ciliary body. Arch Ophthalmol 2010;128(3):380-1.

4. Davidorf FH, Craig E, Birnbaum L, Wakely P, Jr. Management of medulloepithelioma of the ciliary body with brachytherapy. Am J Ophthalmol 2002;133(6):841-3.

5. Kaliki S, Shields CL, Eagle RC, Jr., et al. Ciliary body medulloepithelioma: analysis of 41 cases. Ophthalmology 2013;120(12):2552-9. 


\section{Figure legend}

Fig 1: Characteristic findings in Medulloepithelioma.

A. Colour photograph showing lens notch with lesion attached to the lens and $\mathbf{B}$. showing clump of cysts on the ciliary body $\mathbf{C}$. Large clump of cysts with underlying white mass - this eye was enucleated due to extensive disease at presentation D. Anterior segment view of medulloepithelioma eroding through the iris. E. Example of pre-treatment B ultrasound scan image F. B ultrasound scan image of the same patient as E, following plaque radiotherapy.
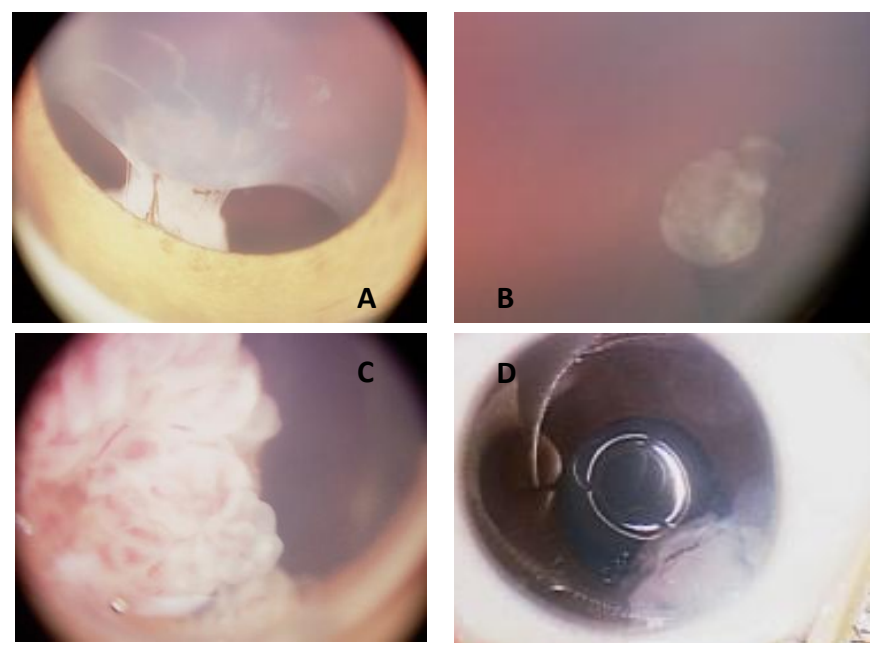

c
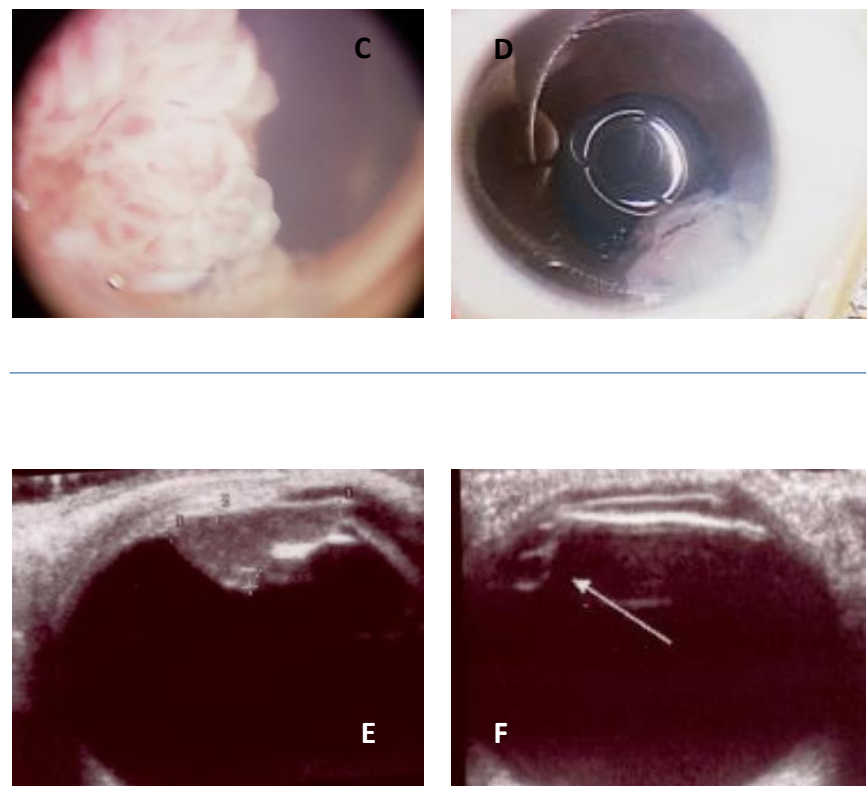
Table 1: Plaque brachytherapy for medulloepithelioma: Clinical Features Feature

No

(\%)

Referring diagnosis

Mass lesion

$1(17)$

Ciliary body cyst

$2(33)$

Medulloepithelioma

$1(17)$

Glaucoma

$1(17)$

Inflammatory eye disease

$1(17)$

Past medical history

None

CHARGE

$1(17)$

syndrome

None

Trauma

Vitreolensectomy

Sectorial cataract

Amblyopia

$1(17)$

Coloboma of CHARGE syndrome

$$
1(17)
$$

\section{Clinical \\ findings at \\ presentation}

Colour of lesion

White

Grey

$3(50)$

Tumour appearance

Ciliary body mass with grape like cystic lesions

Corrugated lesion with cystic changes and overlying pigment

Associated features

Lens notch

Sector cataract

Iris coloboma

Anterior synechiae

Ectropion uveae with iris neovascularisation

Quadrants invovled

Superotemporal

Inferotemporal

Inferonasal

Inferotemporal and superotemporal

$1(17)$

CHARGE syndrome: coloboma of the eye; heart anomaly; choanal atresia; retardation of mental and somatic development; genital/urinary abnormalities; ear abnormalities and/or deafness. 
Table 2: Visual acuity results before and after Ru-106 plaque brachytherapy for medulloepithelioma.

Visual Acuity outcomes

\begin{tabular}{|c|c|c|c|c|c|c|}
\hline Patient & $\begin{array}{l}\text { VA before } \\
\text { treatment }\end{array}$ & $\begin{array}{l}\text { Age } \\
\text { (months) }\end{array}$ & $\begin{array}{l}\text { Method } \\
\text { used }\end{array}$ & $\begin{array}{l}\text { VA after } \\
\text { treatment }\end{array}$ & $\begin{array}{l}\text { Age } \\
\text { (months) }\end{array}$ & Method used \\
\hline 1 & $6 / 24$ & 60 & Snellen & $6 / 19$ & 71 & Snellen \\
\hline 2 & $6 / 19$ & 36 & $\begin{array}{l}\text { Cardiff } \\
\text { cards }\end{array}$ & $6 / 7$ & 51 & Snellen \\
\hline 3 & $6 / 75$ & 9 & Keeler & $6 / 19$ & 16 & Cardiff cards \\
\hline 4 & $6 / 12$ & 9 & $\begin{array}{l}\text { Cardiff } \\
\text { cards }\end{array}$ & $6 / 7.6$ & 51 & Kay pictures \\
\hline 5 & $6 / 24$ & 132 & Snellen & $6 / 38$ & 137 & Snellen \\
\hline 6 & $\begin{array}{l}\text { Perception } \\
\text { light }\end{array}$ & 60 & & $\mathrm{~N} / \mathrm{A}$ & 92 & Enucleated \\
\hline
\end{tabular}

VA - visual acuity 